\title{
Dr. Norberto Alejandro Lanza, 1972-2014
}

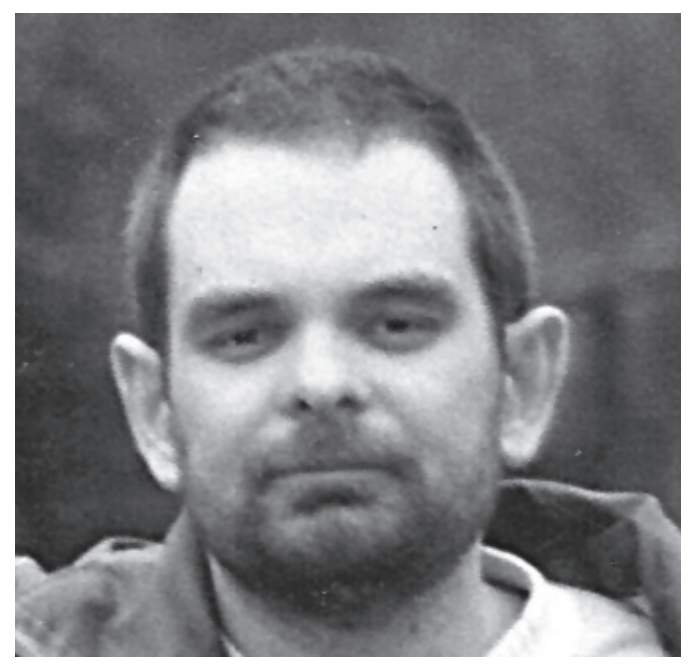

El último 25 de Agosto, a los 41 años de edad falleció el Doctor Norberto Alejandro Lanza. Nunca es sencillo despedir a un amigo, pero menos aun cuando quien nos deja lo hace tan temprano. En estas breves líneas quisiera expresar lo que para muchos de nosotros es un duro golpe. Por lo general este tipo de recordatorios suelen hacer énfasis en los logros profesionales. Por el contrario, en este caso me permitiré exceder ese límite, no sólo destacando sus aportes como investigador sino también compartiendo algunos aspectos personales que dan muestra de su bondad y calidad humana.

Norberto era un científico joven, con un excelente futuro. Estudiamos juntos la Licenciatura en Ciencias Biológicas en la Universidad Nacional de Mar del Plata. Su carrera no fue simple. Recorrió caminos difíciles hasta lograr sus objetivos, afrontando trabajos tan disimiles como empleado comercial u observador de pesca del Instituto Nacional de Investigación y Desarrollo Pesquero. Finalmente logró su graduación con éxito, siendo el primer graduado de la Facultad de Ciencias Exactas y Naturales cuyo tema de investigación se orientó a la antropología biológica, bajo la dirección del Dr. Ricardo Guichón, a través del análisis paleodemográfico de poblaciones patagónicas y el cual resultó uno de los pocos aportes realizados hasta el momento en ese sentido. Durante ese periodo tuvo además una estrecha relación con los Dres.
José A. Cocilovo y Héctor H. Varela, quienes lo apoyaron en sus investigaciones. Como consecuencia de sus trabajos, pude iniciar mis propias investigaciones con Ricardo, graduarme y continuar mi tesis doctoral en un área similar. En ese sentido, Norberto fue decisivo para mi carrera. De no ser por su influencia casi con total seguridad yo no estaría escribiendo estas líneas, porque sencillamente mi carrera habría tomado un curso completamente diferente. También durante ese periodo, un involuntario error de Norberto produjo que conociera casualmente a la que hoy es mi esposa y madre de mi hijo Nicolás. Por eso, tengo que agradecer a Norberto dos de mis mayores logros, mi familia y mi trabajo, algo que nunca pude decirle personalmente.

Luego de su graduación como Licenciado, sus trabajos continuaron ligados a la demografía, esta vez de las poblaciones Tobas y Wichis del Noreste Argentino. En las Jornadas de la AABA de 2001 en Puerto Madryn, conoció a la Dra. Claudia Valeggia quien estaba buscando un biólogo joven para trabajar en comunidades actuales. Fue una decisión difícil para Norberto. Sabía que era una posibilidad de trabajo importante pero que las condiciones serían duras. $\mathrm{Su}$ espíritu ejemplar, su vocación y su fuerza interior lo llevaron a afrontar ese trabajo aún, en ocasiones, a costa de su salud. Se radicó primero en Formosa y luego en Resistencia, alejado de sus padres, su hermano y su Tandil natal. Dedicó gran parte de su tiempo a estudiar y comprender la forma de vida de esas comunidades, compartiendo con ellas largos periodos, a veces durante meses, en ambientes inhóspitos, sin acceso a la mayoría de las comodidades a las cuales estamos acostumbrados. Lo motivaba no sólo su tarea científica, sino la posibilidad de ayudar a esas personas a afrontar sus muchos problemas de salud, alimentación y relación con nuestra sociedad. Ese alto nivel de compromiso es sólo una muestra del enorme espíritu humano que caracterizaba a Norberto.

Durante ese periodo logró su mayor producción científica en asociación con la Dra. Valeg-

doi:10.17139/raab.2015.0017.01.02 
gia, publicando información valiosa acerca de la demografía de las comunidades Toba y Wichi, en especial acerca de su nutrición y fertilidad. Como resultado logró su Doctorado en Ciencias Biológicas en la Universidad Nacional de Córdoba, bajo la dirección de la Dra. Valeggia y el Dr. Enrique Peláez y con la estrecha ayuda y colaboración de la Dra. Sonia Colantonio y el Dr. Héctor H. Varela, quienes sabían que Norberto bien valía el esfuerzo. Realizó sus investigaciones durante los últimos 10 años con profunda dedicación, vocación y pasión. También en esos años formó su familia junto a Carolina, con quien tuvieron a Simón, su pequeño y adorable niño.

En los últimos tres años fue integrante del Consejo Nacional de Investigaciones Científicas y Técnicas como Investigador Asistente, con un gran futuro. Tristemente, poco tiempo después de su designación también llegó el diagnóstico de una enfermedad contra la que luchó por más de dos años y que finalmente no pudo superar.

Parece injusto. Una vida no puede contarse en unas pocas líneas, así nada más. Nuestras conquistas profesionales son importantes, pero sólo a la luz de quienes somos como personas y Norberto es un ejemplo de eso. Su joven carrera no le permitió dejar un legado extenso, pero la marca que dejó en todos con quienes trabajó y muchos de nosotros con quienes compartió su amistad, van mucho más allá de los resultados, las publicaciones y los congresos. Norberto fue parte importante de un gran grupo de amigos con quienes disfrutamos hermosos momentos de una hermosa época de nuestras vidas, de los cuales nos quedan incontables recuerdos imborrables y alegres. Somos muchos quienes lo extrañamos y valoramos antes, ahora y lo seguiremos haciendo siempre, por su honestidad, su alegría (su risa efusiva todavía está presente) y su optimismo permanente y contagioso. En lo personal, las Jornadas Nacionales de Antropología Biológica, que nos permitían acortar las distancias geográficas y reencontrarnos como si el tiempo no hubiera pasado, nunca volverán a ser lo mismo. Pasaré esos días buscando a mi amigo.

A sus padres y hermano, su esposa e hijo y sus muchos amigos nos deja un enorme vacío que ya no será ocupado. Hasta siempre Norber.

Jorge A. Suby

Mi agradecimiento a los Dres. Sonia Colantonio, Sergio Avena, Ricardo Guichón y Marina Sardi por sus comentarios y colaboración en la redacción de este texto. 